- Letter

\title{
Comparison of Cancer Prevalence in Physicians with That of the General Population, and Important Considerations
}

\author{
Yousef Veisani ${ }^{1}$, Ali Delpisheh ${ }^{2, *}$ \\ 'Psychosocial Injuries Research Center, Ilam University of Medical Sciences, Ilam, Iran \\ ${ }^{2}$ Department of Clinical Epidemiology, Ilam University of Medical Sciences, Ilam, Iran
}

\section{To the Editor}

We read with great interest the article by Kim et al. ${ }^{1)}$ entitled "Cancer prevalence among physicians in Korea: a single center study" published in the March issue of the journal. The authors reported that in Korea, physicians have a higher prevalence of cancer compared to the general population, and that cancer prevalence in male and female physicians was 2.47 fold and 3.94-fold higher, respectively, than the expected prevalence of the general population. ${ }^{1)}$ However, we have some concerns about this comparison procedure. In most studies, age is considered a predictor for cancer development, and so age is an important confounder in crude comparisons. ${ }^{2,3)}$ Therefore, we propose that controlling for age in this case must be done using an indirect age adjustment.

Indirect adjustments are used for age adjustment of morbidity data when the numbers of events for each age-specific stratum are not available. ${ }^{4)}$ In the study by Kim et al., ${ }^{1)}$ the agespecific stratum were: $<35$ years, $35-45$ years, $45-55$ years, 55 64 years, and $\geq 65$ years. The expected number of cancers in physicians must be calculated by applying the standard rate (incidence rates of cancer in each age-specific stratum in the general population), and multiplying by the number of physicians in each stratum of the study. Subsequently, for each agespecific stratum, the ratio of the total number of observed events and the expected numbers of cancers provides an estimate for comparing cancer prevalence in physicians to that in general population, which serves as the source of the reference rates; this ratio is known as the standardized incidence ratio.

In conclusion, we think that this article makes valuable points about cancer among physicians, but that comparisons with the general population must adjust for age using an indirect age adjustment to eliminate the potential confounder.

\section{CONFLICT OF INTEREST}

No potential conflict of interest relevant to this article was reported.

\section{REFERENCES}

1. Kim HL, Park HJ, Sim YH, Choi EY, Shim KW, Lee SW, et al. Cancer prevalence among physicians in Korea: a single center study. Korean J Fam Med 2016;37:91-6.

2. Jung KW, Park S, Kong HJ, Won YJ, Boo YK, Shin HR, et al. Cancer statistics in Korea: incidence, mortality and survival in 2006-2007. J Korean Med Sci 2010;25:1113-21.

3. Veisani Y, Delpisheh A, Sayehmiri K, Rahimi E. Demographic and histological predictors of survival in patients with gastric and esophageal carcinoma. Iran Red Crescent Med J 2013;15:547-53.

4. Jones ME, Swerdlow AJ. Bias in the standardized mortality ratio when using general population rates to estimate expected number of deaths. Am J Epidemiol 1998;148:1012-7. 